\title{
Interactive effects of nitrogen and light on growth rates and RUBISCO content of small and large centric diatoms
}

\author{
Gang $\mathrm{Li}^{1,2} \cdot$ Douglas A. Campbell ${ }^{1}$ (i)
}

Received: 1 June 2016/Accepted: 17 August 2016/Published online: 26 August 2016

(c) The Author(s) 2016. This article is published with open access at Springerlink.com

\begin{abstract}
Among marine phytoplankton groups, diatoms span the widest range of cell size, with resulting effects upon their nitrogen uptake, photosynthesis and growth responses to light. We grew two strains of marine centric diatoms differing by $\sim 4$ orders of magnitude in cell biovolume in high (enriched artificial seawater with $\sim 500 \mu \mathrm{mol} \mathrm{L}{ }^{-1} \mu \mathrm{mol} \mathrm{L}^{-1} \mathrm{NO}_{3}{ }^{-}$) and lower-nitrogen (enriched artificial seawater with $<10 \mu \mathrm{mol} \mathrm{L}{ }^{-1} \mathrm{NO}_{3}^{-}$) media, across a range of growth light levels. Nitrogen and total protein per cell decreased with increasing growth light in both species when grown under the lower-nitrogen media. Cells growing under lower-nitrogen media increased their cellular allocation to RUBISCO and their rate of electron transport away from PSII, for the smaller diatom under low growth light and for the larger diatom across the range of growth lights. The smaller coastal diatom Thalassiosira pseudonana is able to exploit high nitrogen in growth media by up-regulating growth rate, but the same high-nitrogen growth media inhibits growth of the larger diatom species.
\end{abstract}

Electronic supplementary material The online version of this article (doi:10.1007/s11120-016-0301-7) contains supplementary material, which is available to authorized users.

Douglas A. Campbell

dcampbell@mta.ca

1 Biology Department, Mount Allison University, Sackville, NB E4L 1G7, Canada

2 Key Laboratory of Tropical Marine Bio-Resources and Ecology, South China Sea Institute of Oceanology, CAS, Guangzhou 510301, China
Keywords Cell size · Chlorophyll · Phytoplankton · Nitrogen metabolism · RUBISCO - Thalassiosira pseudonana $\cdot$ Thalassiosira punctigera

\section{Introduction}

Nitrogen is critical for marine phytoplankton to build abundant cellular materials including proteins and nucleic acids to support their growth and cell division (Finkel et al. 2010; Wu et al. 2014b; Li et al. 2015). One of these nitrogen-rich materials the ribulose-1,5-bisphosphate carboxylase oxygenase (RUBISCO) protein is particularly important, because this bifunctional enzyme catalyzes the initial step of photosynthetic carbon reduction by combining $\mathrm{CO}_{2}$ with ribulose-1,5-bisphosphate (RuBP) (Mizohata et al. 2002), fixing inorganic carbon to organic matter (Kroth 2015). Nitrogen availability can affect the cellular content of RUBISCO with consequent effects upon phytoplankton carbon assimilation (Wilhelm et al. 2006), particularly under N-limited conditions where RUBISCO has been suggested to act as an $\mathrm{N}$ reservoir in some species (Falkowski et al. 1989). Available nitrogen is indeed considered as the proximal limiting factor for marine primary production (Gruber and Galloway 2008; Moore et al. 2013) in much of the modern ocean. At the other extreme, nitrogen compounds have diverse toxic effects, including inhibition of photosystem II (PSII) (Drath et al. 2008).

Marine diatoms are one of the dominant groups of phytoplankton (Wilhelm et al. 2006) in the modern ocean (Bowler et al. 2010) and account for approximately $20 \%$ of global primary productivity (Field et al. 1998). Diatoms also span a wide size range across species from $<2 \mu \mathrm{m}$ to over $200 \mu \mathrm{m}$ in equivalent spherical diameter, giving over eight orders of magnitude in cell volume (Beardall et al. 2009) 
Finkel et al., 2010). Diatom cell size affects many physiological processes, including light energy absorption (Finkel 2001; Key et al. 2010), photosynthesis and respiration (Wu et al. 2014a; López-Sandoval et al. 2014), nutrient diffusion and uptake (Raven 1998; Raven and Kübler 2002; Marañón et al. 2013), and ultimately affects their growth (Mei et al. 2011; Marañón et al. 2013; Wu et al. 2014a).

Small phytoplankton cells have a higher surface area-tovolume ratio and can have lower nutrient requirements for growth (Raven 1998; Finkel et al. 2010); thus, they often dominate in nitrogen-limited and clear oceanic waters (Clark et al. 2013). Furthermore, pigment packaging in large phytoplankton can lead to a decline in light absorption per unit of pigment-protein complex (Finkel 2001; Key et al. 2010; Clark et al. 2013), and thus, a decrease in captured photons per unit of metabolic nitrogen invested into pigment-protein complexes (Raven 1984; Wu et al. 2014b) and carbon assimilation per RUBSICO molecule (Wu et al. 2014b), again conferring advantages to smaller phytoplankton. The prevalence of larger phytoplankton cells in eutrophic and brackish coastal waters can be explained by enhanced resistance to predation (Ward et al. 2012), greater nutrient storage capacity (Grover 2011) and potentially lower metabolic costs to withstand and exploit fluctuating light because of lower susceptibility to photoinactivation of PSII (Key et al. 2010). We found that under near-saturating growth light and media with highnitrogen larger diatoms invested more cellular nitrogen to RUBISCO than did smaller ones, to counter a lower achieved RUBISCO turnover rate (Wu et al. 2014b), a finding that parallels increased allocations to RUBISCO in cold water diatoms where RUBISCO performance is kinetically limited (Losh et al. 2013; Young et al. 2015). To explain our finding of slower achieved RUBISCO turnover in larger diatoms (Wu et al. 2014b), we hypothesized that in higher-nitrogen (HN) media large cells have luxury accumulation of RUBISCO protein that in turn lowers their achieved performance per unit RUBISCO. To test this hypothesis, we grew two representative diatom strains with a $\sim 4$ orders of magnitude difference in cell biovolume, small Thalassiosira pseudonana $\left(\sim 40 \mu \mathrm{m}^{3}\right)$ and large T. punctigera $\left(\sim 300,000 \mu \mathrm{m}^{3}\right)$ in turbidostats across a range of growth light, in lower-nitrogen (LN) media to attempt to limit cellular luxury accumulation of RUBISCO protein, compared with cells grown in a typical laboratory $\mathrm{HN}$ media. We determined the cellular nitrogen content and nitrogen allocations to chlorophyll $a(\mathrm{Chl} a)$, PSII and RUBISCO, as well as light capture and electron transport parameters of the small and large diatoms across the nitrogen levels and growth light ranges, and analyzed in parallel how changing RUBISCO contents and turnover rate interact with changes in growth rates.

\section{Materials and methods}

\section{Culture protocol and growth rate}

Two marine centric diatom strains T. pseudonana (CCMP 1335) and Thalassiosira punctigera (CCAP 1085/19) were obtained from the Provasoli-Guillard National Center of Marine Phytoplankton and cultured in rectangular cuvettes (450 mL volume) of FMT-150 photobioreactors with two$\mathrm{cm}$ optical pathlength for illumination from a flat array of blue LED lights facing the rear face of the cuvette (Photon Systems Instruments, Drasov, Czech Republic) at $18{ }^{\circ} \mathrm{C}$. We used a high-nitrogen media [HN, enriched artificial seawater $\left(\right.$ ESAW)] with $\sim 550 \mu \mathrm{mol} \mathrm{L}{ }^{-1} \mathrm{NO}_{3}{ }^{-}$(Berges et al. 2001), originally from Harrison et al. (1980), except with $54.5 \mu \mathrm{mol} \mathrm{L}{ }^{-1} \mathrm{Si}$ and $0.82 \mu \mathrm{mol} \mathrm{L}{ }^{-1} \mathrm{Sr}$ to limit precipitation during autoclaving. This $\mathrm{HN}$ media maintained $\sim 500 \mu \mathrm{mol} \mathrm{L}{ }^{-1} \mathrm{NO}_{3}^{-}$, in the face of cellular uptake in the turbidostat cultures. We also used a LN media ( $\mathrm{LN}, \sim 55 \mu \mathrm{mol} \mathrm{L}{ }^{-1} \mathrm{NO}_{3}{ }^{-}$), the same ESAW except with one-tenth of the nitrogen level of $\mathrm{HN}$ media, corrected with equal sodium bicarbonate to equivalent total alkalinity. The LN media maintained $\sim 5-10 \mu \mathrm{mol} \mathrm{L}{ }^{-1} \mathrm{NO}_{3}{ }^{-}$in the turbidostat cultures. We gently mixed the cultures with a curtain of bubbles emitted from four apertures across the cuvette bottom with outdoor fresh air that was filtered through a $0.2-\mu \mathrm{m}$ micro-filter and bubbled through sterile distilled water for humidification before bubbling through the culture cuvette. We provided continuous growth light measured with a microspherical quantum sensor (US-SQS, Walz, Germany). The light levels in the culture vessels filled with media were set to 30,180 and $380 \mu \mathrm{mol}$ photons $\mathrm{m}^{-2} \mathrm{~s}^{-1}$ for T. pseudonana, but to 30,90 and $180 \mu \mathrm{mol}$ photons $\mathrm{m}^{-2} \mathrm{~s}^{-1}$ for $T$. punctigera, because the $T$. punctigera growth was already inhibited by $180 \mu \mathrm{mol}$ photons $\mathrm{m}^{-2} \mathrm{~s}^{-1}$, it would not grow under $380 \mu \mathrm{mol}$ photons $\mathrm{m}^{-2} \mathrm{~s}^{-1}$ in our turbidostats with continuous light.

As described in detail for a previous, separate, project (Li and Campbell 2013), we grew each experimental replicate culture from initial inoculation for 5-6 generations without dilution in batch mode to reach a culture suspension density set point for subsequent turbidostat mode, which was monitored continuously using the onboard fluorescence sensor to track pigment content in the bioreactors. When the fluorescence value reached the set point, the bioreactors activated a peristaltic pump to dilute the 450-mL culture with a $10 \%$ volumetric addition of media delivered from a reservoir, which was continuously pre-bubbled with a fresh air stream before adding to the cultures. We used cell counts (data not shown) to calibrate the fluorescence detector set point to control the culture cell suspension density to $3.6 \pm 1.8 \times 10^{5}$ cells $\mathrm{mL}^{-1}$ for 
T. pseudonana and $650 \pm 110$ cells $\mathrm{mL}^{-1}$ for $T$. punctigera. The variation in cell number across treatments (20-50\% SD) resulted mainly from changing pigment contents per cell across growth lights and thus differences in fluorescence signal per cell. We accepted a variation in cell number $\mathrm{mL}^{-1}$ across our treatments to keep the pigment-based bio-optical culture thickness and thus light attenuation, comparable across the treatments. Under these turbidostat growth conditions, the cells depleted the $\mathrm{NO}_{3}{ }^{-}$ concentration within the culture volume to $\sim 500 \mu \mathrm{mol} \mathrm{L}^{-1}$ under $\mathrm{HN}$ and to $<10 \mu \mathrm{mol} \mathrm{L}^{-1}$ under $\mathrm{LN}$ media. 3.5 $\mathrm{L}$ of media in the reservoir supported $\sim 9.5$ cellular generations of turbidostat growth for each replicate culture under the set conditions of light and nitrogen, before we harvested for physiological and biochemical analyses. Depending upon the achieved growth rate, which varied with growth light, nitrogen and species, the temporal duration of each turbidostat run ranged from 160 to $200 \mathrm{~h}$. We calculated the specific growth rate for a given culture replicate by using the onboard detector to monitor optical density at $680 \mathrm{~nm}$ and then fitting the increase with time with an exponential growth function for the interval between each turbidostat $10 \%$ dilution cycle. We then averaged the exponential rates from the final ten cycles of turbidostat dilution to estimate the growth rate for each turbidostat replicate for each growth condition $(\mathrm{Li}$ and Campbell 2013). We grew three or four separate turbidostat replicate cultures of each species under each combination of light and media, for a total of 39 separate turbidostat runs.

\section{Chlorophyll fluorescence measurements}

At the end of each growth period we took out 2-mL culture from each turbidostat cuvette, incubated in darkness for 5 min within a cuvette with temperature control $\left(18^{\circ} \mathrm{C}\right)$ and measured the chlorophyll fluorescence with a fluorometer (PSI FL 3500, Photon Systems Instruments, Czech Republic) using the fast repetition rate fluorescence technique (Kolber et al. 1998). A series of $40 \times 1.2 \mu$ s flashlets of blue light were applied over $128 \mu \mathrm{s} \quad(455 \mathrm{~nm}$; $\sim 100,000 \mu \mathrm{mol}$ photons $\mathrm{m}^{-2} \mathrm{~s}^{-1}$ ) and were provided to progressively close PSII reaction centers. The resulting FRR induction curve was analyzed with the PSIWORX script for MATLAB (Audrey Barnett, www.sourceforge. net), to define $F_{0}$, the base line fluorescence cells after 5 min darkness, $F_{M}$, the maximum fluorescence with all PSII closed and $\sigma_{\text {PSII }}\left(10^{-20} \mathrm{~m}^{2}\right.$ quanta $\left.{ }^{-1}\right)$, the effective absorbance cross section serving PSII photochemistry in the dark-regulated cells. After a 2-s dark period, we applied a second FRR induction to test whether the initial FRR flashlet train perturbed the cells. We then activated an actinic blue light to the growth light level for $2 \mathrm{~min}$; again, we captured the FRR induction curves to extract parameters in illuminated cells, to define $F_{\mathrm{S}}$, the fluorescence in light acclimated state, $F_{\mathrm{M}}^{\prime}$, the maximum fluorescence with all PSII closed and $\sigma_{\text {PSII }}^{\prime}\left(10^{-20} \mathrm{~m}^{2}\right.$ quanta $\left.^{-1}\right)$, the effective absorbance cross section serving PSII photochemistry in the light acclimated state. We then applied an FRR induction after a 2-s dark period again, to allow reopening of closed PSII centers. There was a slight drop in the level of fluorescence from $F_{\mathrm{S}}$ to $F_{02 \mathrm{~s}}^{\prime}$, the baseline fluorescence with all PSII open but still in light acclimated state.

We calculated the maximum photochemical yield in dark-adapted cells as:

$F_{\mathrm{V}} / F_{\mathrm{M}}=\left(F_{\mathrm{M}}-F_{0}\right) / F_{\mathrm{M}} ;$

We also used the magnitude of any increase from $F_{M}^{\prime}$ to $F_{\mathrm{M} 2 \mathrm{~s}}^{\prime}$ to apply a proportional correction to $F_{02 \mathrm{~s}}^{\prime}$ to estimate the actual level of $F_{0}^{\prime}$ under illumination:

$F_{0}^{\prime}=F_{02 \mathrm{~s}}^{\prime} \times\left\{1-\left[\left(F_{\mathrm{M} 2 \mathrm{~s}}^{\prime}-F_{\mathrm{M}}^{\prime}\right) / F_{\mathrm{M} 2 \mathrm{~s}}^{\prime}\right]\right\}$

We estimated the electron transport rate away from PSII following (Huot and Babin 2010) as:

PSII electron transport $=\sigma_{\mathrm{PSII}}^{\prime} \times I \times q_{\mathrm{P}}$,

where $\sigma_{\mathrm{PSII}}^{\prime}\left(\mathrm{m}^{2}\right.$ quanta $\left.^{-1}\right)$ is the effective absorbance cross section serving PSII photochemistry at growth light I (photons $\left.\mathrm{m}^{-2} \mathrm{~s}^{-1}\right)$ and $q_{\mathrm{P}}\left(F_{\mathrm{M}}^{\prime}-F_{\mathrm{S}}\right) /\left(F_{\mathrm{M}}^{\prime}-F^{\prime}{ }_{0}\right)$ is the proportion of PSII instantaneously open and ready to perform photochemistry under light I. We also used the FRR data and PSIWORX MATLAB to extract the life times for fluorescence relaxation after the saturating flashlet train, $\tau_{1}$ and $\tau_{2}$, to measure the downstream capacity to carry electrons away from PSII (Kolber et al. 1998).

\section{Cell density, protein and chlorophyll $a$ measurements}

At the end of each turbidostat growth period, we took duplicate 2-mL culture samples, fixed in Lugol's acid solution and measured the cell suspension density with a Coulter Z2 counter (Beckman Instruments, FL, USA) for $T$. pseudonana and with a Sedgwick Rafter chamber under a microscope for T. punctigera. Simultaneously, we vacuumfiltered $50 \mathrm{~mL}$ of culture sample onto a binder-free Whatman GF/F glass fiber filter ( $25 \mathrm{~mm}$ in diameter), which was immediately flash frozen in liquid nitrogen and stored at $-80{ }^{\circ} \mathrm{C}$ until later analyses of protein and chlorophyll.

Immunoquantitations of specific protein subunits from total protein extracts followed (Brown et al. 2008). Briefly, total protein was extracted from the frozen filters and $450 \mu \mathrm{L}$ of $1 \times$ denaturing extraction buffer $\left(0.1375 \mathrm{~mol} \mathrm{~L}^{-1}\right.$ TRIS buffer, $0.075 \mathrm{~mol} \mathrm{~L}^{-1}$ LDS, $1.075 \mathrm{~mol} \mathrm{~L}^{-1}$ glycerol, $0.5 \mathrm{mmol} \mathrm{L}^{-1}$ EDTA, $0.1 \mathrm{mg} \mathrm{mL}^{-1}$ Pefabloc) (Brown et al. 
2008) for three cycles of $60 \mathrm{~s}$ at $6.5 \mathrm{~m} \mathrm{~s}^{-1}$ using a MPBio FastPrep ${ }^{\circledR}-24$ with bead lysing matrix D (SKU 116913050). Total protein in the extracts was determined using Bio-Rad DC protein assay kit (500-0116) with known bovine gamma globulin standards. Samples containing $0.5 \mu \mathrm{g}$ of total protein were loaded on 4-12\% acrylamideprecast NuPAGE gels (Invitrogen) to determine RUBISCO large subunit (RbcL), run in parallel with a range of $1500,750,375$ and $187.5 \mathrm{fmol}$ RbcL standard per standard lane (Agrisera, www. agrisera.se, AS01 017S) to establish a standard curve. To determine PSII PsbA subunit, we loaded $1 \mu \mathrm{g}$ of total protein per lane, run in parallel with a range of 125, 62.5, 31.25 and 15.625 fmol PsbA standard per standard lane (Agrisera, www.agrisera.se, AS01 016S). Electrophoresis was run for $25 \mathrm{~min}$ at $200 \mathrm{~V}$ and the proteins were transferred to a polyvinylidene fluoride (PVDF) membrane for $60 \mathrm{~min}$ at $30 \mathrm{~V}$ for RbcL and $20 \mathrm{~V}$ for PsbA. After the membrane blocking in $2 \%$ ECL Advance blocking reagent (GE Healthcare) in $20 \mathrm{mmol} \mathrm{L}^{-1}$ Tris, $137 \mathrm{mmol} \mathrm{L}^{-1}$ sodium chloride ( $\mathrm{pH} 7.6$ ) with $0.1 \%$ (v/v) Tween-20 (TBS-T) overnight at $4{ }^{\circ} \mathrm{C}$, a primary antibody (Agrisera, AS03 037 and AS05 084, 1:20,000 in $2 \%$ ECL Advance blocking dilution) was applied, followed by an anti-rabbit secondary antibody coupled with horseradish peroxidase (Agrisera, AS09 602, 1:20,000). The membranes were then developed by chemoluminescence using ECL Advance (GE Biosciences) and imaged under a CCD imager (BioRadVersaDoc 4000MP). Finally, the RbcL and PsbA protein quantitation was determined by fitting the sample signal values to the protein standard curves, taking care that all sample signals fell within the range of protein standard curve and that no band signals were saturated (Brown et al. 2008).

For Chl $a$ measurement, $50 \mu \mathrm{L}$ of protein extract was added to $450 \mu \mathrm{L} 90 \%$ acetone (v/v) saturated with magnesium carbonate; after 15 min extraction in the dark at $4{ }^{\circ} \mathrm{C}$ and 2 min centrifugation $(13,000 \mathrm{~g})$, we measured the absorbance of the supernatant at 664, 630 and $750 \mathrm{~nm}$ using a UV/VIS photospectrometer (UV-1800, Shimadzu, Japan). The concentration of the Chl $a$ in the extract ( $\mu \mathrm{g}$ $\mathrm{Chl} a \mathrm{~mL}^{-1}$ ) was estimated following (Jeffrey and Humphrey 1975):

$[\mathrm{Chl} a]=11.47 \times\left(A_{664}-A_{750}\right)-0.4 \times\left(A_{630}-A_{750}\right)$

\section{Carbon and nitrogen analyses}

At the end of each turbidostat growth period, we filtered $50 \mathrm{~mL}$ of culture onto a pre-combusted $\left(5 \mathrm{~h}, 450{ }^{\circ} \mathrm{C}\right)$ Whatman $\mathrm{GF} / \mathrm{F}$ glass fiber filter $(13 \mathrm{~mm}$ in diameter), rinsed with $10 \mathrm{~mL}$ of $50 \mathrm{mmol} \mathrm{HCl} \mathrm{L}^{-1}$ to remove inorganic carbon, dried at $55{ }^{\circ} \mathrm{C}$ for $12 \mathrm{~h}$ and stored in a desiccator for later analyses. Contents of carbon and nitrogen were measured with a Vario EL III Elemental Analyzer (Elementar, Hanau, Germany).

\section{Data analysis}

The responses of growth rate to culture growth light were fitted with either linear regressions or the equation of Eilers and Peeters (1988):

$\mu=I /\left(a \times I^{2}+b \times I+c\right)$

where $\mu$ is growth rate $\left(\right.$ day $\left.^{-1}\right)$ at the particular light level; I is the growth light ( $\mu$ mol photons $\mathrm{m}^{-2} \mathrm{~s}^{-1}$ ) and $a, b$ and $c$ are fitted parameters and

$\mu_{\max }=1 /(b+2 \sqrt{a \times c})$.

We estimated apparent carbon assimilation per RUBISCO active site $\left(\mathrm{C} \mathrm{RbcL}^{-1} \mathrm{~s}^{-1}\right)$ as:

RUBISCO turnover rate $\left(\mathrm{C} \mathrm{RbcL}^{-1} \mathrm{~s}^{-1}\right)$

$$
=\left(\mathrm{Ccell}^{-1}\right) \times\left(\mathrm{e}^{\mu}-1\right) \times\left(\text { cell RbcL }{ }^{-1}\right)
$$

We used ANOVA with Bonferroni posttests (Prism 5, Graphpad Software) and comparisons of linear and nonlinear curve fits to detect significant differences $(p<0.05)$ in parameters between cultures from $\mathrm{LN}$ and $\mathrm{HN}$ media of each species. In figures, we include the $95 \%$ confidence intervals on regression fits. We only plot and report linear regressions with slopes significantly different from 0 . We used $t$ tests to detect significant differences $(p<0.05)$ between variables measured under $\mathrm{LN}$ and $\mathrm{HN}$ under each growth light.

\section{Results}

The cell growth rate of $T$. pseudonana growing in HN media increased with growth light from low $(\sim 30 \mu \mathrm{mol}$ photons $\left.\mathrm{m}^{-2} \mathrm{~s}^{-1}\right)$ to moderate levels $(\sim 180 \mu \mathrm{mol}$ photons $\mathrm{m}^{-2} \mathrm{~s}^{-1}$ ) reaching a fitted $\mu_{\max }$ of 1.5 day $^{-1}$ but then decreased under higher light (Fig. 1a). Under LN $30 \mu \mathrm{mol}$ photons $\mathrm{m}^{-2} \mathrm{~s}^{-1}$ was already growth-saturating for $T$. pseudonana (Fig. 1a), albeit at a lower $\mu_{\max }$ than under HN $(p<0.05)$. The growth rate of T. punctigera in HN media was much slower than $T$. pseudonana $(p<0.05)$ but showed a qualitatively similar pattern of response to light, increasing with growth light from $\sim 30$ to $\sim 90 \mu \mathrm{mol}$ photons $\mathrm{m}^{-2} \mathrm{~s}^{-1}$ with a fitted $\mu_{\max }$ of $0.39 \mathrm{day}^{-1}$ but then decreasing under higher light (Fig. 1b). The growth rate of $T$. punctigera in LN media was significantly $(p<0.05)$ higher than in HN media, particularly under the lower growth light (Fig. 1b). For T. punctigera under LN $30 \mu \mathrm{mol}$ photons $\mathrm{m}^{-2} \mathrm{~s}^{-1}$ was already growth-saturating, with a $\mu_{\max }$ higher $(p<0.05)$ under $\mathrm{LN}$ than under $\mathrm{HN}$. 

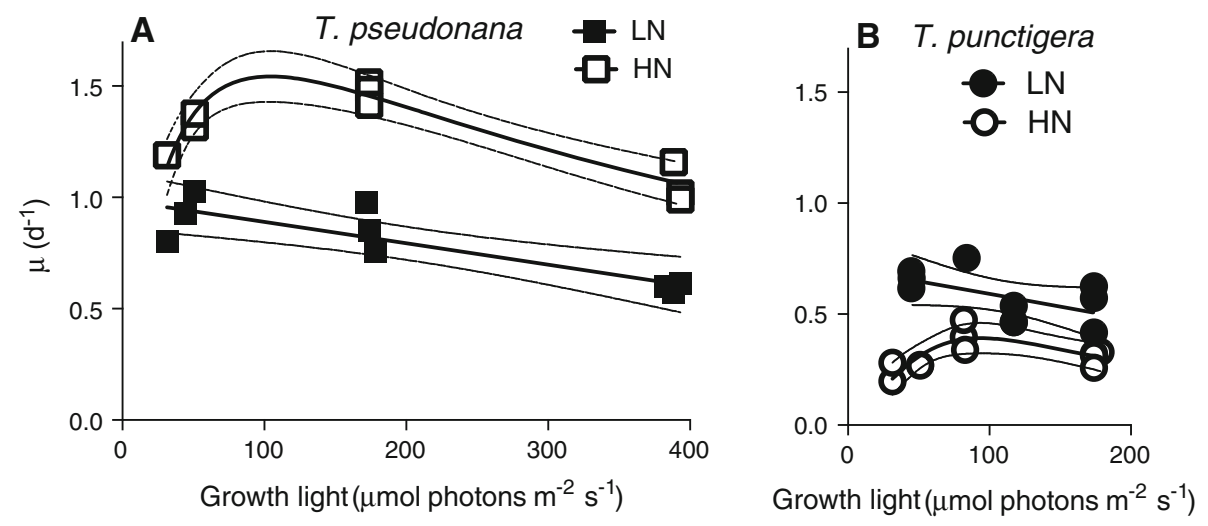

Fig. 1 Growth rate $\left(\mu\right.$, day $\left.^{-1}\right)$ versus culture growth light $(\mu \mathrm{mol}$ photons $\mathrm{m}^{-2} \mathrm{~s}^{-1}$ ) of the small diatom a $T$. pseudonana and b large diatom $T$. punctigera under low- (LN, filled symbols) and highnitrogen media (HN, open symbols). Solid lines light response curves (Peeters and Eilers 1978; Eilers and Peeters 1988) or linear regressions; thin dotted lines show $95 \%$ confidence intervals on the

The mass $\mathrm{C}: \mathrm{N}$ ratio increased for both species with increasing growth light in LN media $(p<0.05)$, but not in $\mathrm{HN}$ media (Table 1). The only significant effect of media $\mathrm{N}$ upon $\mathrm{C}: \mathrm{N}$ ratio was for $T$. punctigera growing at the highest growth light $(p<0.05)$. Chl $a$ per cell decreased significantly $(p<0.05)$ with increasing growth light for both species in LN and in HN media, with no significant effects of media nitrogen (Table 1).

In $T$. pseudonana, total cellular protein content increased significantly $(p<0.05)$ under low media nitrogen and the lowest growth light. In $T$. punctigera, the fitted curves. Note that there were small variations in the light sources among our three bioreactor units, so we plotted the specific growth rates and other parameters versus the actual light level applied to a given culture condition replicate, resulting in small offsets in data points along the $X$ axes of plots, which slightly improved the statistical power of our curve fitting

protein content showed scatter among replicates, but showed a significant decrease under $\mathrm{HN}$ at the highest growth light $(p<0.05)$ (Table 1$)$.

In T. pseudonana, the molar contents of PsbA subunit decreased in LN media with increasing growth light $(p<0.05)$. In the larger $T$. punctigera, PsbA contents decreased with increasing growth light in $\mathrm{HN}$ media $(p<0.05)$ (Table 1). The molar contents of RbcL subunit in $\mathrm{HN}$ media increased with increasing growth light for $T$. pseudonana but decreased for T. punctigera as growth light increased (Table 1). High-N media significantly decreased

Table 1 Carbon per cell (pg cell ${ }^{-1}$ ), mass C:N ratio, and cellular contents of chlorophyll $a$ (pg cell ${ }^{-1}$ ), total protein (pg cell ${ }^{-1}$ ), photosystem II PsbA subunit (amol cell ${ }^{-1}$ ) and RUBISCO large subunit (RbcL, amol cell ${ }^{-1}$ ) of $T$. pseudonana and T. punctigera under low- (LN) and highnitrogen media $(\mathrm{HN})$ across three levels of growth light

\begin{tabular}{|c|c|c|c|c|c|c|c|c|}
\hline Strains & $\begin{array}{l}\text { Growth light } \\
(\mu \mathrm{mol} \\
\left.\text { photons } \mathrm{m}^{-2} \mathrm{~s}^{-1}\right)\end{array}$ & $\begin{array}{l}\text { Media N } \\
\left(\mu \mathrm{mol} \mathrm{L}{ }^{-1}\right)\end{array}$ & $\begin{array}{l}\text { Carbon } \\
\left(\text { pg cell }^{-1}\right)\end{array}$ & $\mathrm{C}: \mathrm{N}$ & $\begin{array}{l}\text { Chla } \\
\left(\text { pg cell }^{-1}\right)\end{array}$ & $\begin{array}{l}\text { Total protein } \\
\left(\mathrm{pg} \text { cell }{ }^{-1}\right)\end{array}$ & $\begin{array}{l}\text { PsbA } \\
(\text { amol } \\
\left.\text { cell }^{-1}\right)\end{array}$ & $\begin{array}{l}\mathrm{RbcL} \\
\left(\text { amol cell }{ }^{-1}\right)\end{array}$ \\
\hline \multirow[t]{6}{*}{ T. pseudonana } & \multirow[t]{2}{*}{30} & 55 & $10.5 \pm 0.52$ & $6.25 \pm 0.20$ & $0.25 \pm 0.03$ & $7.12 \pm 0.65$ & $0.73 \pm 0.08$ & $21.2 \pm 0.91$ \\
\hline & & 550 & $8.29 \pm 0.84$ & $5.89 \pm 0.50$ & $0.27 \pm 0.07$ & $\mathbf{4 . 8 8} \pm 0.73$ & $0.30 \pm 0.04$ & $7.23 \pm 0.92$ \\
\hline & \multirow[t]{2}{*}{180} & 55 & $9.25 \pm 2.00$ & $6.41 \pm 0.12$ & $0.20 \pm 0.04$ & $4.49 \pm 0.41$ & $0.43 \pm 0.03$ & $8.68 \pm 1.44$ \\
\hline & & 550 & $8.09 \pm 0.48$ & $6.42 \pm 0.32$ & $0.13 \pm 0.03$ & $4.61 \pm 0.23$ & $0.33 \pm 0.07$ & $8.30 \pm 1.45$ \\
\hline & \multirow[t]{2}{*}{380} & 55 & $8.91 \pm 1.41$ & $7.67 \pm 0.52$ & $0.08 \pm 0.02$ & $4.31 \pm 1.28$ & $0.40 \pm 0.07$ & $8.25 \pm 1.52$ \\
\hline & & 550 & $8.71 \pm 0.87$ & $6.34 \pm 0.87$ & $0.09 \pm 0.01$ & $4.64 \pm 0.37$ & $0.34 \pm 0.05$ & $10.0 \pm 2.55$ \\
\hline \multirow[t]{6}{*}{ T. punctigera } & \multirow[t]{2}{*}{30} & 55 & $5669 \pm 560$ & $5.30 \pm 0.64$ & $142 \pm 37.6$ & $4424 \pm 1221$ & $246 \pm 50.7$ & $9578 \pm 5547$ \\
\hline & & 550 & $7675 \pm 430$ & $4.82 \pm 0.32$ & $115 \pm 5.31$ & $5703 \pm 893$ & $230 \pm 64.2$ & $3524 \pm 777$ \\
\hline & \multirow[t]{2}{*}{90} & 55 & $6752 \pm 434$ & $7.61 \pm 2.10$ & $83.5 \pm 21.3$ & $3992 \pm 1192$ & $215 \pm 103$ & $5178 \pm 2128$ \\
\hline & & 550 & $6921 \pm 186$ & $5.24 \pm 0.50$ & $79.1 \pm 24.1$ & $4475 \pm 778$ & $208 \pm 44.6$ & $3138 \pm 530$ \\
\hline & \multirow[t]{2}{*}{180} & 55 & $8281 \pm 1421$ & $9.28 \pm 1.88$ & $59.4 \pm 28.5$ & $4225 \pm 54.3$ & $206 \pm 82.3$ & $6977 \pm 3219$ \\
\hline & & 550 & $7160 \pm 1565$ & $5.20 \pm 0.59$ & $58.3 \pm 14.8$ & $3503 \pm 430$ & $168 \pm 60.8$ & $2657 \pm 420$ \\
\hline
\end{tabular}

The values are presented as mean $\pm \operatorname{SD}(n=3$ or 4$)$; bold numbers show significant differences in cultures from LN and HN conditions $(p<0.05)$ 
the RbcL content of $T$. pseudonana at the lowest growth light and that of $T$. punctigera at all growth lights when compared to LN media ( $p<0.05)$.

Cellular nitrogen content in $T$. pseudonana and in $T$. punctigera decreased significantly $(p<0.05)$ as growth light increased in $\mathrm{LN}$ media, but not under $\mathrm{HN}$ media (Fig. 2a, b). The low-N media also lowered T. punctigera cellular $\mathrm{N}$ content across all growth light conditions compared to $\mathrm{HN}(p<0.05)$ (Fig. 2b). We estimated the fraction of cellular nitrogen allocated to Chl $a$ (Table 1), to PSII (extrapolated from molar contents of the PsbA subunit, Table 1) and to RUBISCO protein (extrapolated from molar contents of the RbcL subunit, Table 1) as in Li et al. (2015). The molar fraction of Chl $a \mathrm{~N}$ to total cellular $\mathrm{N}$ (Chl $a \mathrm{~N}$ :total $\mathrm{N}$ ) in $T$. pseudonana decreased with increasing growth light $(p<0.05)$, with no significant effect of media $\mathrm{N}$ (Fig. 2c). Under high nitrogen, the Chl a $\mathrm{N}$ :total $\mathrm{N}$ in $T$. punctigera decreased with increasing
Fig. 2 Nitrogen per cell (pg cell $^{-1}$ ) versus culture growth light ( $\mu \mathrm{mol}$ photons $\mathrm{m}^{-2} \mathrm{~s}^{-1}$ ) of a $T$. pseudonana and $\mathbf{b} T$. punctigera under low- (LN, filled symbols) and highnitrogen media (HN, open symbols). Solid line in a: linear regression for growth light response for $T$. pseudonana from LN condition only. Solid line in $\mathbf{b}$ : linear regression for growth light response for $T$. punctigera from LN condition only; thin dotted lines show $95 \%$ confidence intervals on the fitted curves. Molar fraction of nitrogen allocated to chlorophyll $a$ relative to total cellular nitrogen (Chl $a$ N:total $\mathrm{N})$ versus culture growth light ( $\mu \mathrm{mol}$ photons $\mathrm{m}^{-2} \mathrm{~s}^{-1}$ ) of $\mathbf{c} T$. pseudonana and $\mathbf{d} T$. punctigera. Solid line in c: linear regression for pooled growth light response for $T$. pseudonana from LN and $\mathrm{HN}$. Lines in $\mathbf{d}$ : polynomial curves for T. punctigera from LN (solid) and HN (dashed). Molar PSII nitrogen-to-total nitrogen ratio (PSII N:total N) versus culture growth light $(\mu \mathrm{mol}$ photons $\mathrm{m}^{-2} \mathrm{~s}^{-1}$ ) of e $T$. pseudonana and $\mathbf{f} T$. punctigera. Lines in e: exponential decay for T. pseudonana from LN (solid) or linear regression from $\mathrm{HN}$ (dashed). Molar RUBISCO $\mathrm{N}$ :total $\mathrm{N}$ ratio versus culture growth light ( $\mu \mathrm{mol}$ photons $\mathrm{m}^{-2}$ $\mathrm{s}^{-1}$ ) of $\mathbf{g} T$. pseudonana and h $T$. punctigera. Lines in $\mathbf{g}$ : exponential decay for $T$. pseudonana from LN (solid) and linear regression from $\mathrm{HN}$ (dashed)
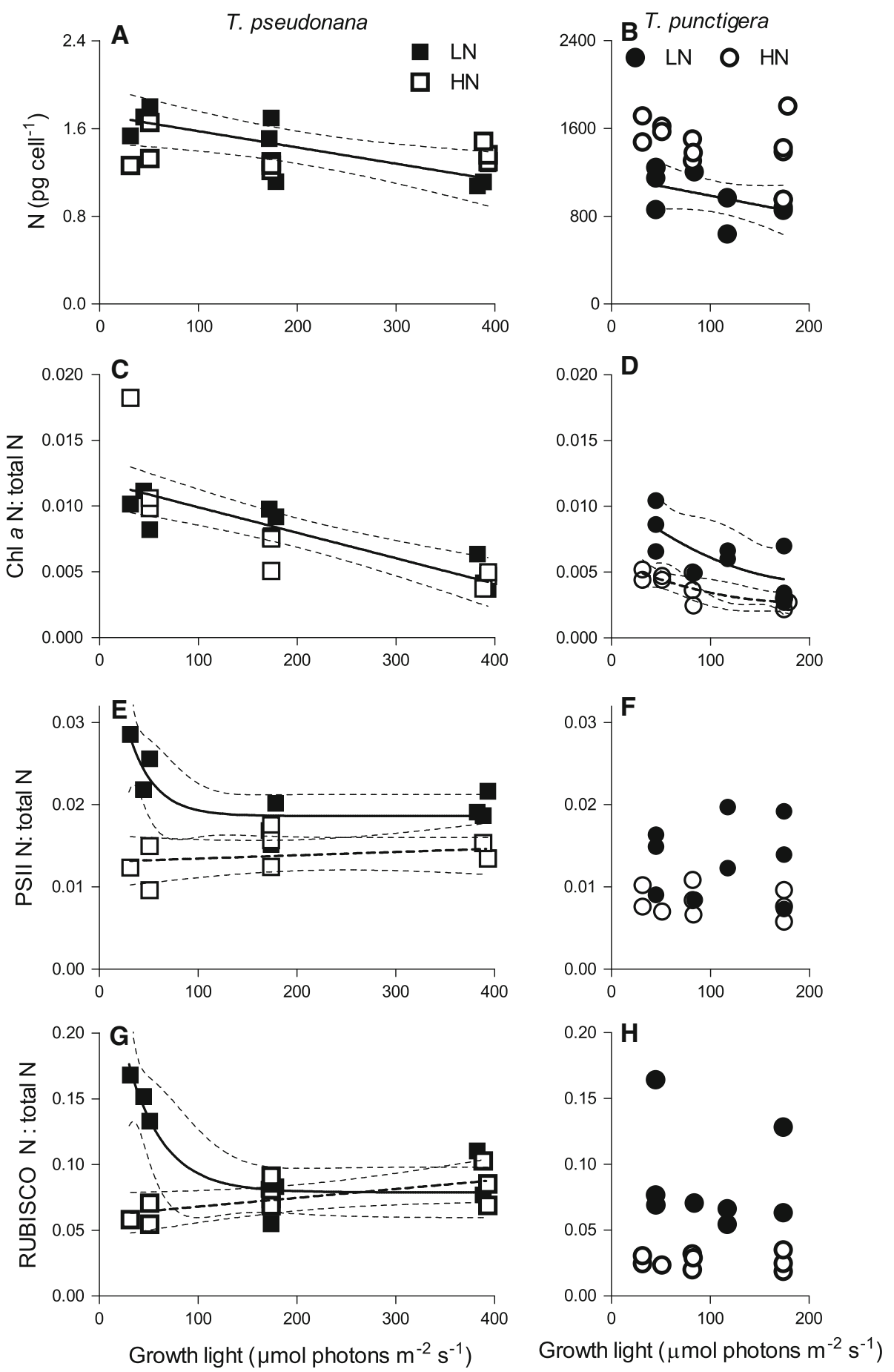
growth light $(p<0.05)$, and was also significantly increased by lower media $\mathrm{N}$ across the growth lights $(p<0.05)$ (Fig. $2 \mathrm{~d}$ ). The PSII N:total $\mathrm{N}$ in T. pseudonana increased under low media $\mathrm{N}$ at lowest growth light (Fig. 2e). The PSII N:total $\mathrm{N}$ in $T$. punctigera varied among replicates but with no apparent trends with growth light nor with media nitrogen level (Fig. 2f). The molar fraction of $\mathrm{N}$ allocated to RUBISCO relative to total cellular $\mathrm{N}$ under high nitrogen increased slightly for $T$. pseudonana as growth light increased, but showed no clear trends for T. punctigera (Fig. $2 \mathrm{~g}, \mathrm{~h}$ ). For T. pseudonana under low growth light, and for T. punctigera across the growth lights low-nitrogen media resulted in increased cellular content of RUBISCO, with a parallel increase in cellular protein content under high light. Thus, our initial goal of using lower media $\mathrm{N}$ to restrict the cellular allocation of $\mathrm{N}$ to RUBISCO failed for both species. Our results do show that in T. punctigera the RUBISCO content under $\mathrm{HN}$ does not likely represent luxury accumulation, because the fractional allocation of $\mathrm{N}$ to RUBISCO increased further under $\mathrm{LN}$ media.

Maximum photochemical quantum yield of PSII $\left(F_{\mathrm{V}} /\right.$ $F_{\mathrm{M}}$ ) was $\sim 0.58$ in $T$. pseudonana with no significant effect of growth light, nor of media nitrogen level (Fig. 3a). The $F_{\mathrm{V}} / F_{\mathrm{M}}$ of $T$. punctigera, in contrast, decreased from 0.44 to 0.32 with increasing growth light in high-nitrogen media, but was somewhat higher in low-nitrogen media (Fig. 3b), showing that the high nitrogen resulted in a sustained down-regulation of PSII function, even under low growth light in $T$. punctigera. The functional absorption cross section for PSII photochemistry $\left(\sigma_{\mathrm{PSII}}\right)$ in $T$. pseudonana decreased with increasing growth light, with no significant nitrogen effects (Fig. 3c), and showed a positive correlation with Chl $a$ per cell (Table 1; Supplemental Figure 1, $R^{2}=0.73$ ). The $\sigma_{\mathrm{PSII}}$ for $T$. punctigera showed no significant effects of growth light nor of media nitrogen level (Fig. 3d). PSII electron transfer rate (ETR) for T. pseudonana increased with increasing growth light from 30 to $380 \mu \mathrm{mol}$ photons $\mathrm{m}^{-2} \mathrm{~s}^{-1}\left(R^{2}=0.92\right)$, with no significant effect of media nitrogen (Fig. 3e). The PSII ETR for $T$. punctigera increased with growth light under low-nitrogen media, but showed a lower response to increasing light under HN media (Fig. 3f) because of lower PSII quantum yield and lower photochemical quenching $\left(q_{\mathrm{P}}\right)$ under HN.

The rate constant for $\left(1 / \tau_{1}, \mathrm{~s}^{-1}\right)$ for PSII reopening after a saturating flash reflects the kinetics of QA-re-oxidation (Kolber et al. 1998) and thus the capacity for downstream metabolism to balance PSII photochemistry. $1 / \tau_{1}$ in $T$. pseudonana showed no statistically significant effects of growth light, nor of media nitrogen level at our level of replication (Fig. $3 \mathrm{~g}$ ). $1 / \tau_{1}$ for $T$. punctigera was significantly $(p<0.05)$ higher in LN media, than in HN media
(Fig. 3h), and accelerated with increasing growth light in LN media, but not in HN media. Thus, in $T$. punctigera the HN media decreased the capacity for electron transport away from PSII, thereby explaining the lower PSII ETR (Fig. 3b, h).

When we plotted growth rate $(\mu)$ against the nitrogen allocation to RUBISCO relative to total cellular nitrogen, a common, saturating, fit (Eilers and Peeters 1988) explained the variation in growth rates for both $T$. pseudonana (LN) and $T$. punctigera $(\mathrm{LN}, \mathrm{HN})\left(R^{2}=0.67\right)$, with growth rate reaching half saturation at a RUBISCO N:total $\mathrm{N}$ of 0.058 . T. pseudonana grown in HN media, however, fell well above this pooled fitted curve (Fig. 4a), achieving higher growth rates at a given allocation RUBISCO N:total N. Similarly, the apparent RUBISCO turnover rate of $T$. pseudonana from LN media and T. punctigera from LN and $\mathrm{HN}$ media showed a negative linear correlation with RUBISCO N:total N $\left(R^{2}=0.87\right)$; but again $T$. pseudonana achieved a higher apparent RUBISCO turnover rate in HN media (Fig. $4 \mathrm{~b}$ ). $1 / \tau_{1}$ shows a common saturating pattern when plotted versus RUBISCO N:total $\mathrm{N}\left(R^{2}=0.48\right)$, for both species across all treatments (Fig. 4c). On a plot of $1 /$ $\tau_{1}$ versus $\mathrm{RbcL}: \mathrm{PsbA}$ ratio, there was a saturating pattern for all treatments of T. punctigera $\left(R^{2}=0.37\right)$, but not for T. pseudonana (Fig. 5a). $\mu$ versus RbcL:PsbA showed a linearly increasing trend for $T$. punctigera $\left(R^{2}=0.59\right)$ (Fig. 5b).

\section{Discussion}

Wu et al. (2014b) found that, compared to small diatoms, larger diatoms had a higher allocation of cellular nitrogen to RUBISCO, but lower achieved carbon assimilation per RUBISCO. Those findings were from diatoms growing semi-continuously in flasks under $f / 2$ media $\left(\sim 850 \mu \mathrm{mol} \mathrm{L} \mathrm{L}^{-1} \mathrm{NO}_{3}{ }^{-}\right)$and $350 \mu \mathrm{mol}$ photons $\mathrm{m}^{-2} \mathrm{~s}^{-1}$ light with a 12:12 Light:Dark cycle. In this study we initially sought to test whether RUBISCO allocation in larger diatom cells represented a luxury accumulation of excess RUBISCO that could account for a low apparent RUBISCO turnover rate (Wu et al. 2014b). We therefore grew these same smaller and larger diatoms as continuous turbidostat cultures using photobioreactors to supply enriched artificial seawater at either $\mathrm{HN}, 550 \mu \mathrm{mol} \mathrm{L}{ }^{-1} \mathrm{NO}_{3}{ }^{-}$, or $\mathrm{LN}, 55 \mu \mathrm{mol} \mathrm{L}{ }^{-1} \mathrm{NO}_{3}^{-}$, under a range of continuous light levels.

We achieved the expected growth limitation by lower culture nitrogen in the smaller $T$. pseudonana, which nevertheless maintained its RbcL content under low nitrogen (Table 1) and thus suffered a decrease in achieved RUBISCO turnover rate (Fig. 4b, closed vs. open squares) under low-nitrogen conditions. In contrast, at the lower 
Fig. 3 Maximum photosystem II photochemical quantum yield $\left(F_{\mathrm{V}} / F_{\mathrm{M}}\right)$ versus culture growth light $\left(\mu \mathrm{mol}\right.$ photons $\left.\mathrm{m}^{-2} \mathrm{~s}^{-1}\right)$ of a $T$. pseudonana and $\mathbf{b} T$. punctigera under low- (LN, filled symbols) and highnitrogen media (HN, open symbols). Solid line in b: linear regression for growth light response for $T$. punctigera from LN condition; thin dotted lines show $95 \%$ confidence intervals on the fitted curves. Functional absorption cross section for PSII photochemistry $\left(\sigma_{\mathrm{PSII}}\right.$, $10^{-20} \mathrm{~m}^{2}$ quanta $^{-1}$ ) versus growth light $(\mu \mathrm{mol}$ photons $\mathrm{m}^{-2} \mathrm{~s}^{-1}$ ) of c $T$. pseudonana and $\mathbf{d} T$. punctigera. Solid line in c: linear regression for pooled growth light response for $T$. pseudonana from $\mathrm{LN}$ and $\mathrm{HN}$ conditions. Electron transfer rate $\left(\mathrm{e}^{-}\right.$PSII $\left.^{-1} \mathrm{~s}^{-1}\right)$ versus growth light ( $\mu \mathrm{mol}$ photons $\mathrm{m}^{-2} \mathrm{~s}^{-1}$ ) of e T. pseudonana and $\mathbf{f} T$. punctigera. Solid line in e: linear regression for pooled growth light response for $T$. pseudonana from $\mathrm{LN}$ and $\mathrm{HN}$ conditions. Lines in $\mathbf{f}$ : linear regressions for growth light response for $T$. punctigera from LN (solid) and HN (dashed) conditions. Slow decay lifetime $\left(\tau_{1}, \mu \mathrm{s}\right)$ of chlorophyll fluorescence versus culture growth light ( $\mu \mathrm{mol}$ photons $\mathrm{m}^{-2}$ $\mathrm{s}^{-1}$ ) of $\mathbf{g}$ T. pseudonana and h $T$. punctigera. Solid line in $\mathbf{g}$ : light response curve (Eilers and Peeters 1988) for pooled $\tau_{1}$ from $\mathrm{LN}$ and $\mathrm{HN}$ conditions. Solid line in $\mathbf{h}$ : linear regression for growth light response for $T$. punctigera from LN condition
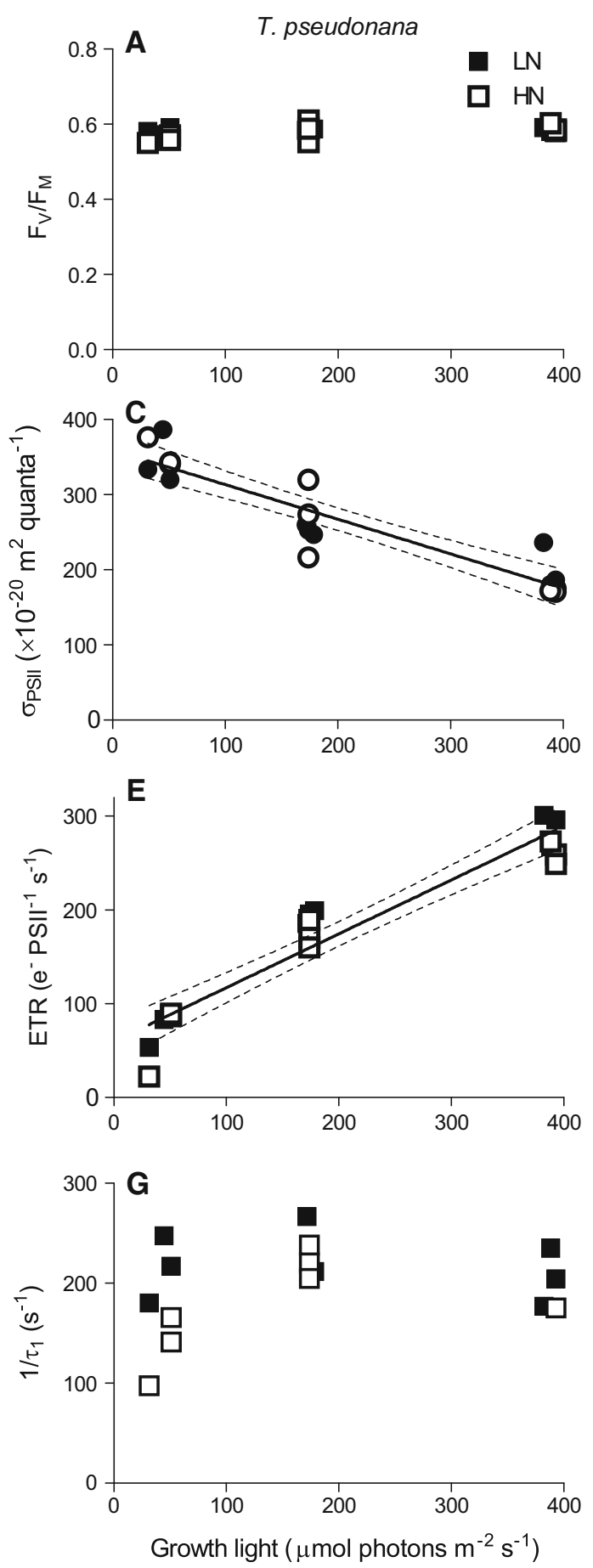
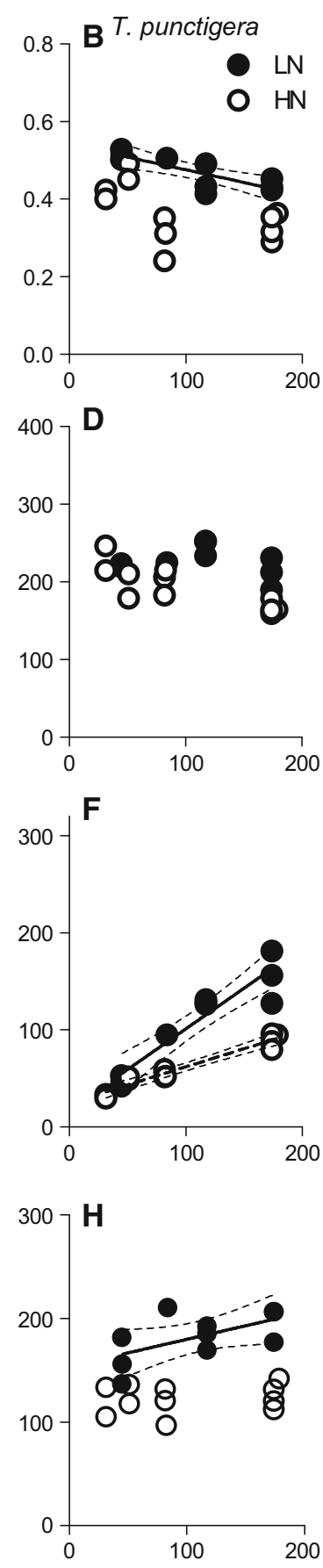

Growth light $\left(\mu \mathrm{mol}\right.$ photons $\mathrm{m}^{-2} \mathrm{~s}^{-1}$ ) culture nitrogen level $\left(<10 \mu \mathrm{mol} \mathrm{L}{ }^{-1} \mathrm{NO}_{3}{ }^{-}\right)$the larger $T$. punctigera supported increased growth rates, particularly under lower light (Fig. 1b), although T. punctigera failed to grow under yet lower conditions of approximately $<5 \mu \mathrm{mol} \mathrm{L} \mathrm{L}^{-1} \mathrm{NO}_{3}{ }^{-}$(data not presented). Therefore, we failed to achieve a reliably growth-limiting $\mathrm{N}$ concentration for $T$. punctigera.

Under LN, the larger diatom T. punctigera actually increased its cellular nitrogen allocation to RUBISCO
(Fig. 2h; Table 1) across the range of growth lights, while in parallel achieving a RUBISCO turnover rate comparable to the rates achieved under HN (Fig. 4b). Thus, the low performance of RUBISCO turnover rate in our larger diatoms in (Wu et al. 2014b) was not attributable to luxury accumulation of excess RUBISCO, but rather to a limitation on their growth rates under high concentrations of $\mathrm{NO}_{3}{ }^{-}$in typical laboratory media. These differences between studies illustrate the complexities of 

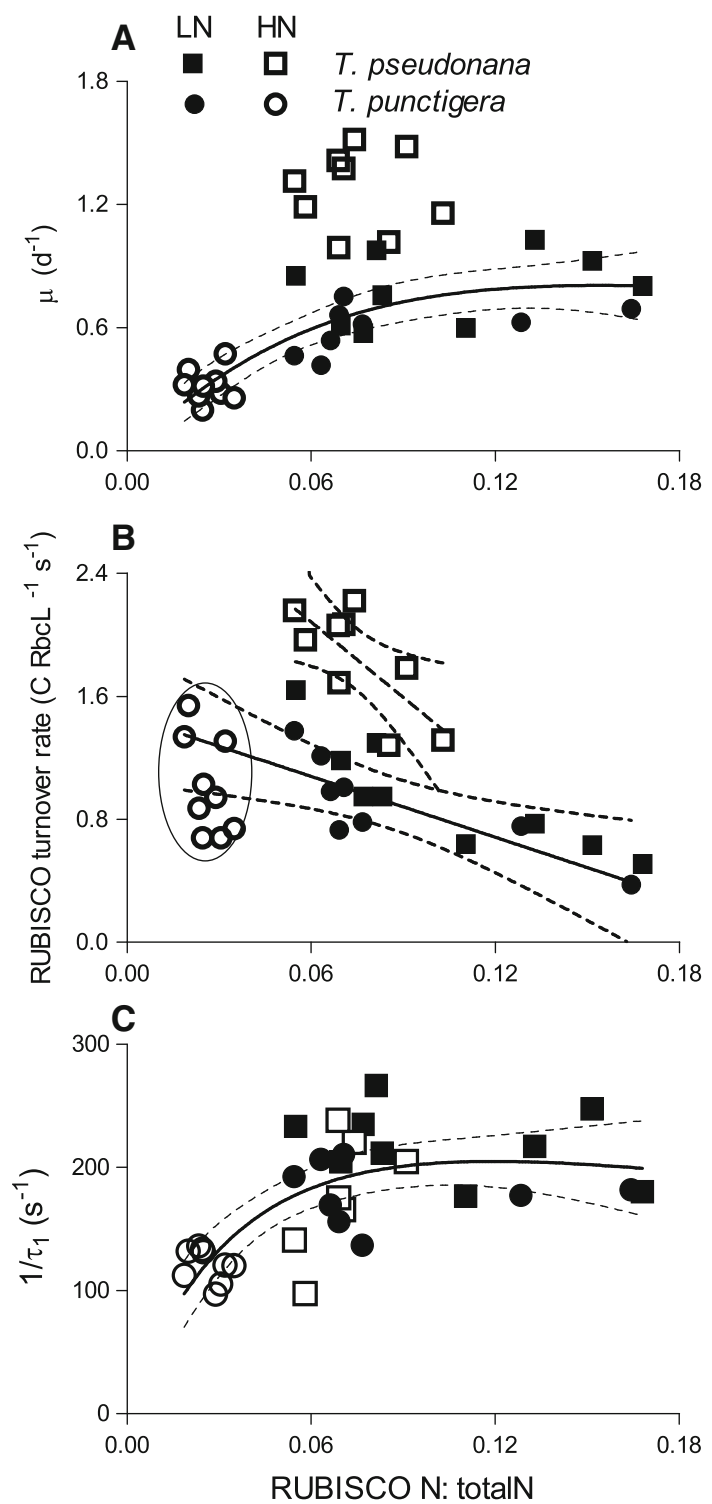

Fig. 4 a Growth rate $\left(\mu\right.$ day $\left.^{-1}\right)$ versus molar RUBISCO N-to-total cellular N ratio (RUBISCO N:total $\mathrm{N}$ ) of $T$. pseudonana (squares) and T. punctigera (circles) under low- (LN, filled symbols) and highnitrogen media (HN, open symbols). A common saturating function (Eilers and Peeters 1988) was fit to pooled data points, except $T$. pseudonana $\mathrm{HN}$ (open squares); thin dotted lines $95 \%$ confidence intervals on the fitted curves. b Apparent RUBISCO turnover rate $\left(\mathrm{C} \mathrm{RbcL} \mathrm{L}^{-1} \mathrm{~s}^{-1}\right.$ ) versus RUBISCO N:total $\mathrm{N}$ of $T$. pseudonana and $T$. punctigera. Solid line linear regression of pooled $\mathrm{C} \mathrm{RbcL}{ }^{-1} \mathrm{~s}^{-1}$ versus RUBISCO N:total $\mathrm{N}$ for T. pseudonana from $\mathrm{LN}$ condition and T. punctigera from $\mathrm{LN}$ and $\mathrm{HN}$ conditions. Oval outlines $T$. punctigera $\mathrm{HN}$ measures, which were included in the pooled regression. Dashed line shows separate regression for T. pseudonana $\mathrm{HN}$ (open squares). c $1 / \tau_{1}\left(\mathrm{~s}^{-1}\right)$, the rate of electron transport away from PSII, versus RUBISCO N:total $\mathrm{N}$ of $T$. pseudonana and $T$. punctigera. Solid line the best response curve fitted with (Peeters and Eilers 1978; Eilers and Peeters 1988)

macromolecular allocations to cellular functions across strains and growth conditions (Young et al. 2016). The different L:D cycles between (Wu et al. 2014a) (12:12
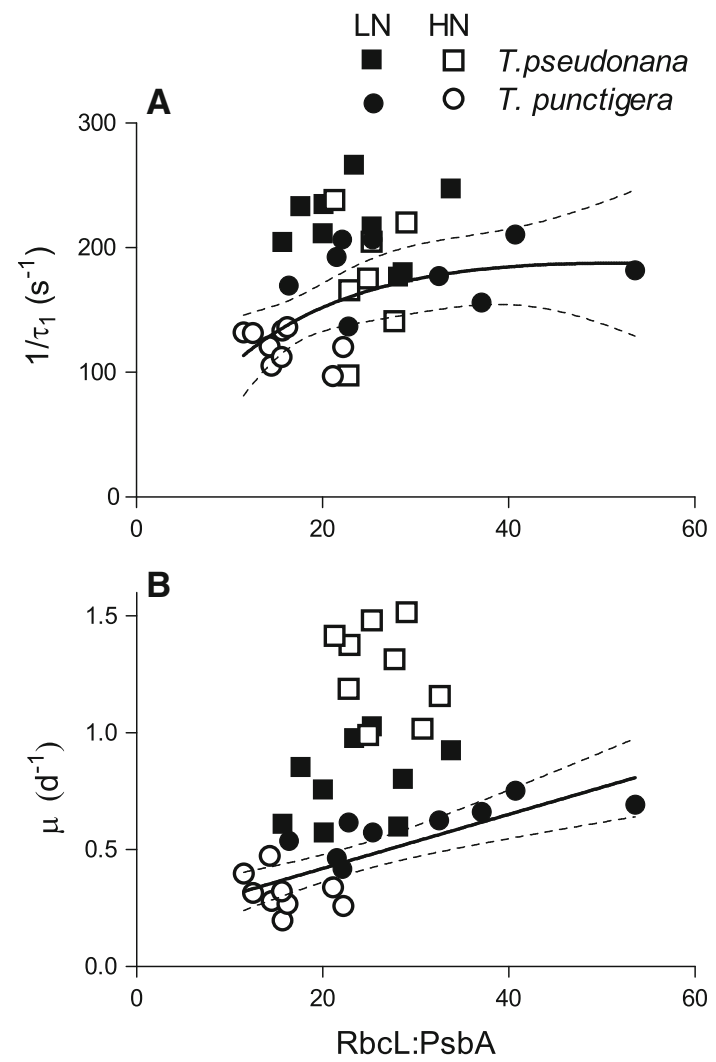

Fig. 5 a $1 / \tau_{1}\left(\mathrm{~s}^{-1}\right)$, the rate of electron transport away from PSII versus RbcL:PsbA ratio of T. pseudonana (squares) and T. punctigera (circles) under low- (LN, filled symbols) and high-nitrogen media (HN, open symbols). Solid lines the best response curve fit (Peeters and Eilers 1978; Eilers and Peeters 1988) for T. punctigera; thin dotted lines show $95 \%$ confidence intervals on the fitted curves. b Growth rate $\left(\mu\right.$, day $\left.^{-1}\right)$ versus RbcL:PsbA ratio of T. pseudonana and T. punctigera under LN and HN conditions. Solid line linear regression of pooled $\mu$ versus RbcL:PsbA for T. punctigera from $\mathrm{LN}$ and $\mathrm{HN}$; thin dotted lines $95 \%$ confidence intervals on the fitted curves

L:D) and herein (24:0 L:D) could also contribute to the differences between the studies as shorter photoperiods increase the achieved RUBISCO turnover rate, particularly for larger diatoms ( $\mathrm{Li}$ and Campbell, unpubl.).

Low $\mathrm{N}$ often limits phytoplankton growth (Mei et al. 2011; Moore et al. 2013; Li and Gao 2014) as indeed found here for T. pseudonana (Fig. 1a). There are two main strategies for phytoplankton to maintain growth rate when the growth environment is not favorable, to increase the abundance of rate-limiting enzymes or to increase the achieved enzymatic rates, as shown in particular by studies of the enzyme responsible for carbon fixation, RUBISCO (Feller and Gerday 2003; Young et al. 2015, 2016). Phytoplankton can thus allocate an increased fraction of their cellular $\mathrm{N}$ to growth rate-limiting enzymes, as for example RUBISCO, to maintain their growth when the media $\mathrm{N}$ source is low, consistent with our results for T. pseudonana grown at low growth light (Fig. $2 \mathrm{~g}$ ) and $T$. punctigera grown across three light levels (Fig. 2h). Meanwhile, the 
lower $\mathrm{N}$ source greatly decreased the achieved activity of RUBISCO in the small $T$. pseudonana but not in the larger T. punctigera (Fig. 4b), indicating differential effects of lower $\mathrm{N}$ source on both the amount and the achieved activity of RUBISCO in the smaller and larger diatom.

In analogy, Young et al. (2015) found that to compensate for slow enzymatic rates at low temperatures, Antarctic diatoms up-regulated both RUBISCO allocation and other cellular proteins needed for $\mathrm{C}$ fixation, to maintain productivity to support the intense spring/summer blooms in high-latitude waters, despite water temperatures close to freezing. Our results are consistent since higher RUBISCO abundance supported higher growth rates of both $T$. pseudonana and $T$. punctigera, but the relation shifted differentially for each species in high- or low-N media (Fig. 4a). T. pseudonana, but not T. punctigera, was able to up-regulate achieved RUBISCO performance to exploit higher levels of nitrogen in the media. Low-nitrogen media up-regulated the nitrogen allocation to RUBISCO rather than to PSII for $T$. punctigera, resulting in a higher RbcL:PsbA ratio (Fig. 5b). This in turn led to faster electron transport away from PSII (Fig. 5a) (Zorz et al. 2015), which might have ameliorated PSII photoinhibition and stimulated the cell growth (Fig. 5b) under LN.

In recent decades, coastal or estuarine nitrogen concentration has increased globally, as in Hong Kong waters where nitrate reaches $40 \mu \mathrm{mol} \mathrm{L}{ }^{-1}$ in summer (Xu et al. 2012), in the Danube River estuary, northwestern Black Sea, where nitrate reached $50 \mu \mathrm{mol} \mathrm{L}^{-1}$ (Möbius and Dähnke 2015) and in the Jiulong River estuary, northern South China Sea, where nitrate reached over $80 \mu \mathrm{mol} \mathrm{L}{ }^{-1}$ (Li et al. 2011). According to our findings (Fig. 1b), such nitrate levels are already well above the optimal growth nitrogen levels for large $T$. punctigera. In contrast, the smaller $T$. pseudonana can successfully exploit yet higher nitrate levels to achieve higher growth rates (Fig. 1a).

\section{Summary}

We grew small and large marine centric diatoms, $T$. pseudonana and $T$. punctigera, in high- and low-nitrogen media, across a range of growth light. Growth-limiting LN media did not significantly lower cellular $\mathrm{N}$ content in the small $T$. pseudonana. In contrast, the same LN media stimulated faster growth in the larger $T$. punctigera, which actually increased cellular nitrogen content under low-nitrogen media compared to $\mathrm{HN}$ media. Furthermore, we found low-nitrogen media increased the cellular RUBISCO content of the smaller $T$. pseudonana at limiting light, but that $T$. pseudonana was able to up-regulate RUBISCO turnover under higher media $\mathrm{N}$. The larger $T$. punctigera showed higher RUBISCO content under low-nitrogen media, in parallel with an increased capacity to carry electrons away from PSII. The larger T. punctigera showed sustained down-regulation of PSII function under high nitrogen (Drath et al. 2008), which was released in parallel with the increase in RUBISCO content under LN, providing a possible mechanism for the differential growth responses between the two diatoms.

\section{Data archiving}

The data for this project are available through the database of Dr. Douglas A. Campbell Lab, phytoplankton.mta.ca.

Acknowledgments We thank four anonymous reviewers for their extensive comments that helped to improve our manuscript. Jessica Grant-Burt did cell count determinations for T. punctigera. Miranda Corkum and Dr. Ina Benner assisted with the $\mathrm{CN}$ analyses.

Funding This work was supported by the Canada Research Chairs program (DC) using equipment supported by the Canada Foundation for Innovation and the New Brunswick Innovation Foundation. GL was supported by CAS Strategic Pilot Science and Technology of China (XDA13020103, XDA11020200), National Natural Science Foundation of China (41206132) and Natural Science Foundation of Guangdong Province, China (2015A030313826).

Open Access This article is distributed under the terms of the Creative Commons Attribution 4.0 International License (http://crea tivecommons.org/licenses/by/4.0/), which permits unrestricted use, distribution, and reproduction in any medium, provided you give appropriate credit to the original author(s) and the source, provide a link to the Creative Commons license, and indicate if changes were made.

\section{References}

Beardall J, Allen D, Bragg J et al (2009) Allometry and stoichiometry of unicellular, colonial and multicellular phytoplankton. New Phytol 181:295-309. doi:10.1111/j.1469-8137.2008.02660.x

Berges JA, Franklin DJ, Harrison PJ (2001) Evolution of an artificial seawater medium: improvements in enriched seawater, artificial water over the last two decades. J Phycol 37:1138-1145. doi:10. 1046/j.1529-8817.2001.01052.x

Bowler C, Vardi A, Allen AE (2010) Oceanographic and biogeochemical Insights from diatom genomes. Annu Rev Mar Sci 2:333-365. doi:10.1146/annurev-marine-120308-081051

Brown C, MacKinnon J, Cockshutt A et al (2008) Flux capacities and acclimation costs in Trichodesmium from the Gulf of Mexico. Mar Biol 154:413-422

Clark JR, Lenton TM, Williams HTP, Daines SJ (2013) Environmental selection and resource allocation determine spatial patterns in picophytoplankton cell size. Limnol Oceanogr 58:1008-1022. doi:10.4319/1o.2013.58.3.1008

Drath M, Kloft N, Batschauer A et al (2008) Ammonia triggers photodamage of photosystem II in the cyanobacterium Synechocystis sp. strain PCC 6803. Plant Physiol 147:206-215. doi:10.1104/pp.108.117218

Eilers PHC, Peeters JCH (1988) A model for the relationship between light intensity and the rate of photosynthesis in phytoplankton. Ecol Model 42:199-215. doi:10.1016/0304-3800(88)90057-9 
Falkowski PG, Sukenik A, Herzig R (1989) Nitrogen limitation in Isochrysis galbana. II. Relative abundance of chloroplast proteins. J Phycol 25:471-478. doi:10.1111/j.1529-8817.1989. tb00252.x

Feller G, Gerday C (2003) Psychrophilic enzymes: hot topics in cold adaptation. Nat Rev Microbiol 1:200-208. doi:10.1038/ nrmicro773

Field CB, Behrenfeld MJ, Randerson JT, Falkowski P (1998) Primary production of the biosphere: integrating terrestrial and oceanic components. Science 281:237-240. doi:10.1126/science.281. 5374.237

Finkel ZV (2001) Light absorption and size scaling of light-limited metabolism in marine diatoms. Limnol Oceanogr 46:86-94. doi:10.4319/lo.2001.46.1.0086

Finkel ZV, Beardall J, Flynn KJ et al (2010) Phytoplankton in a changing world: cell size and elemental stoichiometry. J Plankton Res 32:119-137. doi:10.1093/plankt/fbp098

Grover JP (2011) Resource storage and competition with spatial and temporal variation in resource availability. Am Nat 178:E124E148. doi:10.1086/662163

Gruber N, Galloway JN (2008) An Earth-system perspective of the global nitrogen cycle. Nature 451:293-296. doi:10.1038/ nature 06592

Harrison PJ, Waters RE, Taylor FJR (1980) A broad spectrum artificial sea water medium for coastal and open ocean phytoplankton1. J Phycol 16:28-35. doi:10.1111/j.0022-3646.1980. 00028.X

Huot Y, Babin M (2010) Overview of fluorescence protocols: theory, basic concepts, and practice. In: Suggett DJ, Prášil O, Borowitzka MA (eds) Chlorophyll $a$ fluorescence in aquatic sciences: methods and applications. Springer, Dordrecht, pp 31-74

Jeffrey S, Humphrey G (1975) New spectrophotometric equations for determining chlorophylls a1, b1, c1 and c2 in higher plants, algae and natural phytoplankton. Biochem Physiol Pflanz 167:191-194

Key T, McCarthy A, Campbell DA et al (2010) Cell size trade-offs govern light exploitation strategies in marine phytoplankton. Environ Microbiol 12:95-104. doi:10.1111/j.1462-2920.2009. 02046.x

Kolber ZS, Prášil O, Falkowski PG (1998) Measurements of variable chlorophyll fluorescence using fast repetition rate techniques: defining methodology and experimental protocols. Biochim Biophys Acta (BBA) Bioenerg 1367:88-106. doi:10.1016/ S0005-2728(98)00135-2

Kroth PG (2015) The biodiversity of carbon assimilation. J Plant Physiol 172:76-81. doi:10.1016/j.jplph.2014.07.021

Li G, Campbell DA (2013) Rising $\mathrm{CO}_{2}$ interacts with growth light and growth rate to alter photosystem II photoinactivation of the coastal diatom Thalassiosira pseudonana. PLoS One 8:e55562. doi:10.1371/journal.pone.0055562

Li G, Gao K (2014) Effects of solar UV radiation on photosynthetic performance of the diatom Skeletonema costatum grown under nitrate limited condition. Algae 29:27-34. doi:10.4490/algae. 2014.29.1.027

Li Y, Cao W, Su C, Hong H (2011) Nutrient sources and composition of recent algal blooms and eutrophication in the northern Jiulong River, Southeast China. Mar Pollut Bull 63:249-254. doi:10. 1016/j.marpolbul.2011.02.021

Li G, Brown CM, Jeans J et al (2015) The nitrogen costs of photosynthesis in a diatom under current and future $\mathrm{pCO}_{2}$. New Phytol 205:533-543. doi:10.1111/nph.13037

López-Sandoval DC, Rodríguez-Ramos T, Cermeño P et al (2014) Photosynthesis and respiration in marine phytoplankton: relationship with cell size, taxonomic affiliation, and growth phase.
J Exp Mar Biol Ecol 457:151-159. doi:10.1016/j.jembe.2014.04. 013

Losh JL, Young JN, Morel FMM (2013) RUBISCO is a small fraction of total protein in marine phytoplankton. New Phytol 198:52-58. doi:10.1111/nph.12143

Marañón E, Cermeño P, López-Sandoval DC et al (2013) Unimodal size scaling of phytoplankton growth and the size dependence of nutrient uptake and use. Ecol Lett 16:371-379. doi:10.1111/ele. 12052

Mei Z, Finkel Z, Irwin A (2011) Phytoplankton growth allometry and size-dependent C:N stoichiometry revealed by a variable quota model. Mar Ecol Prog Ser 434:29-43. doi:10.3354/meps09149

Mizohata E, Matsumura H, Okano Y et al (2002) Crystal structure of activated ribulose-1,5-bisphosphate carboxylase/oxygenase from green alga Chlamydomonas reinhardtii complexed with 2-carboxyarabinitol-1,5-bisphosphate. J Mol Biol 316:679-691. doi:10.1006/jmbi.2001.5381

Möbius J, Dähnke K (2015) Nitrate drawdown and its unexpected isotope effect in the Danube estuarine transition zone: $\mathrm{N}$ isotope dynamics in the Danube Delta. Limnol Oceanogr 60:1008-1019. doi: $10.1002 /$ lno. 10068

Moore CM, Mills MM, Arrigo KR et al (2013) Processes and patterns of oceanic nutrient limitation. Nat Geosci 6:701-710. doi:10. 1038/ngeo 1765

Peeters JCH, Eilers P (1978) The relationship between light intensity and photosynthesis-a simple mathematical model. Hydrobiol Bull 12:134-136. doi:10.1007/BF02260714

Raven JA (1984) A cost-benefit analysis of photon absorption by photosynthetic unicells. New Phytol 98:593-625

Raven JA (1998) The twelfth Tansley Lecture. Small is beautiful: the picophytoplankton. Funct Ecol 12:503-513. doi:10.1046/j.13652435.1998.00233.x

Raven JA, Kübler JE (2002) New light on the scaling of metabolic rate with the size of algae. J Phycol 38:11-16

Ward BA, Dutkiewicz S, Jahn O, Follows MJ (2012) A sizestructured food-web model for the global ocean. Limnol Oceanogr 57:1877-1891. doi:10.4319/lo.2012.57.6.1877

Wilhelm C, Büchel C, Fisahn J et al (2006) The regulation of carbon and nutrient assimilation in diatoms is significantly different from green algae. Protist 157:91-124. doi:10.1016/j.protis.2006. 02.003

Wu Y, Campbell DA, Irwin AJ et al (2014a) Ocean acidification enhances the growth rate of larger diatoms. Limnol Oceanogr 59:1027-1034. doi:10.4319/1o.2014.59.3.1027

Wu Y, Jeans J, Suggett DJ et al (2014b) Large centric diatoms allocate more cellular nitrogen to photosynthesis to counter slower RUBISCO turnover rates. Front Mar Sci. doi:10.3389/ fmars.2014.00068

$\mathrm{Xu}$ J, Glibert PM, Liu H et al (2012) Nitrogen sources and rates of phytoplankton uptake in different regions of Hong Kong waters in summer. Estuaries Coasts 35:559-571. doi:10.1007/s12237011-9456-9

Young JN, Goldman JAL, Kranz SA et al (2015) Slow carboxylation of RUBISCO constrains the rate of carbon fixation during Antarctic phytoplankton blooms. New Phytol 205:172-181. doi:10.1111/nph.13021

Young JN, Heureux AMC, Sharwood RE et al (2016) Large variation in the RUBISCO kinetics of diatoms reveals diversity among their carbon-concentrating mechanisms. $J$ Exp Bot 67:3445-3456. doi:10.1093/jxb/erw163

Zorz JK, Allanach JR, Murphy CD et al (2015) The RUBISCO to photosystem II ratio limits the maximum photosynthetic rate in picocyanobacteria. Life 5:403-417. doi:10.3390/life5010403 